\title{
A TRANSNACIONALIZAÇÃO DA IDENTIDADE CONSTITUCIONAL NA AMÉRICA LATINA: PORQUE NÃO UMA IDENTIDADE INTERAMERICANA DOS DIREITOS HUMANOS NO BRASIL PÓS-1988?
}

\author{
Mateus Trinta Bruzaca ${ }^{1}$
}

\section{RESUMO}

Este artigo se ocupa de investigar o papel da Corte Interamericana de Direitos Humanos na reconstrução da identidade constitucional no Brasil pós-1988. A pesquisa desenvolveu-se segundo uma abordagem qualitativa, com amparo em método hipotético-dedutivo e mediante técnica de revisão bibliográfica. Para tanto, a dogmática de Carl Schmitt e Michel Rosenfeld são revisadas, argumentando-se a inadequação da leitura schmittiana de identidade constitucional, de modo a balizar o estudo segundo uma concepção desconstrutivista e pluralista. Conclui-se, ao cabo, que a transnacionalização da identidade constitucional encontra obstáculos de natureza estrutural e sócio-histórica, que, no Brasil, restringem a incorporação do discurso jurídico interamericano.

Palavras-chave: Corte Interamericana; identidade constitucional; Brasil; transnacionalização; discurso jurídico.

\section{THE TRANSNATIONALIZATION OF THE CONSTITUTIONAL IDENTITY IN LATIN AMERICA: WHY NOT AN INTER-AMERICAN IDENTITY OF HUMAN RIGHTS IN POST-1988 BRAZIL?}

\begin{abstract}
This article investigates the role of the Inter-American Court of Human Rights in the reconstruction of constitutional identity in post-1988 Brazil. The research was developed according to a qualitative approach, a hypothetical-deductive method and through the technique of literature review. Therefore, the dogmatics of Carl Schmitt and Michel Rosenfeld are revised, arguing the inadequacy of the Schmittian reading of constitutional identity, guiding the study according to a deconstructivist and pluralist slant. It is concluded, in the end, that the transnationalization of constitutional identity encounters structural and socio-historical obstacles, which, in Brazil, restrict the incorporation of the inter-American legal discourse.
\end{abstract}

Keywords: Inter-American Court; constitutional identity; Brazil; transnationalization; legal discourse.

\section{INTRODUÇÃO}

\footnotetext{
1 Mestrando em Direito pela Universidade Federal de Pernambuco (UFPE). Bacharel em Direito pela Universidade Federal do Maranhão (UFMA). Pesquisador vinculado ao grupo de pesquisa Direito Internacional e Direitos Humanos (CNPq/UFPE) e ao projeto integrador Direito Internacional sem Fronteiras (DisF). Advogado. E-mail: mateusbruzaca@ufpe.br
} 
Com o processo de reconstrução dogmática da teoria dos direitos humanos no final do século XX a proposta westfaliana de organização dos Estados se subleva, cedendo espaço a atuação de novos atores internacionais e supranacionais, os quais se articulam em redes multilaterais focadas em temas políticos, econômicos e jurídicos. Representantes da modernidade reflexiva (Anthony Giddens e Ulrich Beck e Scott Lash, e.g.) sustentam que esta ordenação das relações sociais a um nível global faz surgir uma comunidade política integrada, com grupos sociais interdependentes e solidários. Outros teóricos, conquanto, acreditam que é temerário idealizar uma ordem mundial que superou o caráter hegemônico e adversarial da política (MOUFFE, 2015).

A despeito das críticas à leitura otimista da realidade pós-Westfaliana serem válida, estes estudos ajudam a desvelar dimensões substanciais às investigações que pretendem observar as variáveis fenomenológicas e juspolíticas do Direito. Anthony Giddens (1991, p. 32), à exemplo, classifica como pós-tradicional a sociedade atual e aduz que as identidades tanto pessoais, quanto normativas e institucionais - tornam-se um projeto reflexivo, dispostas a negar e contestar traços que foram legados, herdados ou construídos segundo uma percepção pré-moderna. As identidades agora, aduz o sociólogo, são constantemente descobertas, construídas e sustentadas ativamente, numa troca sociocultural de dimensões globais, onde a lógica que sustenta a autoidentificação é a da ruptura com o passado (GIDDENS, 1991).

O constitucionalismo, neste novo enquadramento, encontra a inevitabilidade de reformulações e, como resposta direta do desenvolvimento de uma comunidade global, cosmopoliza suas estruturas teóricas e institucionais, pautando-se na racionalidade jurídica pós-positivista e nos contornos político-sociais de extraterritorialização e pluralização de discursos e concepções de bem. Logo, diante das renovações epistêmicas promovidas pela realidade pós-tradicional de Giddens (1991) a questão que se coloca nesta pesquisa é como responde a identidade constitucional dos Estados ao processo de mundialização, materializado sobremaneira na interlocução do discurso constitucional com dotações de conhecimento jurídico produzidas por atores internacionais judiciais e quase-judiciais e ruptura com tradições constitucionais inviáveis ao contexto transnacional.

Para este propósito a pesquisa recorre aos estudos de Michel Rosenfeld (2010) sobre identidade do sujeito constitucional, buscando aplicar tal teoria à realidade do Sistema Interamericano de Proteção aos Direitos Humanos (SIDH). Assim, é exposta a definição conceitual de identidade e sujeito constitucional. A fim de delimitar e justificar 
adequadamente a concepção de "identidade constitucional" à qual a pesquisa se vincula, a teoria de Michel Rosenfeld (2010) é contraposta às abordagens essencialistas pautadas em Carl Schmitt (2007). Defende-se, desta forma, uma compreensão pluralista e reflexiva do fenômeno investigado.

A posteriori, a pesquisa propõe o desenvolvimento dogmático de uma "identidade interamericana do sujeito de direitos humanos", concepção teorética que se materializa no discurso jurídico da Corte Interamericana de Direitos Humanos (Corte IDH). Se analisa, pois, como essa identidade interamericana se decanta no esquadro constitucional pátrio, destacando, na oportunidade, a natureza estrutural e sociocultural dos limites que restringem a transnacionalização da identidade constitucional no Brasil pós-1988.

\section{A IDENTIDADE CONSTITUCIONAL: DEFINIÇÃO CONCEITUAL E ABORDAGENS DOGMÁTICAS}

A assertiva de Del Vecchio (1980, p. 432) de que "[...] o modo pelo qual se organiza o poder humano supremo e regula o exercício do Estado se chama constituição" não basta para exprimir a realidade complexa do fenômeno constitucional. A constituição, em verdade, congrega uma situação política que se renova constantemente mediante atos de vontade humana. Compreender a constituição, pois, como um processo estanque e subvencionado apenas pelas ambições de assembleias que carregam o poder constituinte originário é ignorar a necessária historicidade e contextualidade social na qual se insere texto e discurso constitucional.

As constituições não se engendram segundo procedimento unívoco, mas envolvem uma constante reinterpretação, reforma e mutação, a fim de salvaguardar sua condição de reflexo jurídico-normativo da realidade político-social do Estado. Neste sentido, a reconstrução e modulação do texto constitucional por iniciativa dos tribunais constitucionais como delineado por teóricos como Francisco Lucas Pires e Brun-Otto Bryde - reafirma que a preservação e desenvolvimento da ordem constitucional significa impreterivelmente a abertura do fenômeno constitucional às evoluções sociais e novas dinâmicas juspolíticas que conformam o Estado Democrático e solicitam, à medida em se normalizam no tecido social, sua cristalização no esquadro constitucional (CANOTILHO, 2010).

Estar-se a pressupor, desta forma, uma percepção sociológica da constituição e a não passividade da norma e do discurso constitucional, os quais devem manter íntima conexão com a realidade das superestruturas político-sociais, de sorte que toda alteração nas formas de 
sociabilidade influencie e module o fenômeno constitucional. (DANTAS, 2016). Nestes termos, viabilizar a reconstrução constitucional trata-se de "[...] dotar a constituição de capacidade de prestação em face da sociedade e dos cidadãos" (CANOTILHO, 2010, p. 1344), concedendo-lhe uma identidade reflexiva, que se compreende como fenômeno da materialização das ambições políticas no mundo jurídico-institucional. Isto é, a legalização das movimentações identitárias e discursivas já naturalizadas na experiência institucional da comunidade política, a fim de preservar ou definir as balizas de uma dada ordem jurídica.

O desenvolvimento constitucional combate, pois, a crise de reflexividade que pode acometer as constituições quando de sua incapacidade em exprimir as expectativas políticas ou de concretizar as ambições jurídicas que lhe foram entronizadas. Logo, é diante do esforço de preservar a reflexividade autopoiética (LUHMANN, 1996) do texto constitucional e a potência pluralista do discurso jurídico-constitucional, que a noção de identidade constitucional se desenvolve a nível dogmático e jurisprudencial.

Antes de compreender, contudo, como o distanciamento do texto constitucional das demandas substanciais que o constitucionalismo global suscita, impactam na afirmação dos direitos humanos e consolidação de valores democráticos, importa delimitar uma concepção pluralista de identidade constitucional, contrapondo-a à visão essencialista que se cristaliza em tribunais nacionais europeus em função da aplicação acrítica da doutrina de Carl Schmitt.

\subsection{A abordagem essencialista de Carl Schmitt e a identidade constitucional como argumento retórico}

A despeito de invariavelmente relacionar-se com a noção de reconstrução e atualização normativa, a investigação da identidade constitucional deixa vislumbrar duas abordagens divergentes no que toca ao impacto das transformações estruturais da sociedade multicêntrica e pós-tradicional na identidade constitucional - uma primeira de viés limitante e estatocêntrico, aplicada por tribunais constitucionais europeus e influência pelo pensamento schmittiano; e uma segunda, construída por teóricos norte-americanos como Michel Rosenfeld (2010) e Gary Jacobson (2011), que procuram normatizar um pluralismo abrangente e - como escreve Jurgen Habermas (2017, p. 490) - renovar a concepção da escola histórica alemã de um direito vivo, que emana do "espírito do povo" (volksgeist).

A primeira abordagem pode ser perfeitamente exemplificada ao se observar o artigo 4.2 do Tratado da União Europeia, onde garante-se aos Estados-membros o respeito à identidade nacional que se reflete na estrutura política e constitucional, obstando intervenções 
externas na comunidade político-constitucional e a consequente transnacionalização do debate democrático. Esta noção de uma identidade nacional que se replica na estrutura constitucional se desenvolve especialmente na Europa, e tem sido utilizada como argumento jurídico por tribunais constitucionais - como na Alemanha, Itália e Hungria - para delimitar os limites de interação e influência entre a esfera supranacional e o direito doméstico (DRINÓCZI, 2019).

Esta abordagem é observada, por exemplo, na atuação do Tribunal Constitucional Federal da Alemanha (BVerfG) em julgados como Solange I (1974), Outright Monetary Transactions (2014) e Lisbon Decision (2009), onde se ponderou que apenas o poder constituinte pode dispor sobre alterações constitucionais, de modo que a integração progressiva predisposta pelo Tratado de Lisboa fere as bases da autodeterminação e dos princípios democráticos e atenta contra a identidade constitucional alemã codificada no artigo 7.3 da German Basic Law (BVerfG, 2009, p. 179). Entende Monika Polzin (2016, p. 419) que o uso da identidade constitucional como barreira à integração regional se retroalimenta da idealização schmittiana consolidada em Constitutional Theory (1917).

Ao escrever sobre os limites da reforma constitucional, Carl Schmitt (p. 150, 2008) ponderou que o poder constituinte acomoda, quando do constitution-making, duas provisões normativas, sendo uma delas representativa da "verdadeira constituição", logo, de natureza fundamental e irretocável. Este ethos constitucional poderia ser emendado apenas pelo poder constituinte originário, de modo que as emendas à constituição - e, portanto, qualquer processo de reconstrução constitucional - poderiam estabelecer-se apenas sobre o pressuposto de que a "identidade da constituição" fosse preservada. Schmitt assume a constituição como uma decisão política fundamental que define a comunidade política e, portanto, não poderia ser eliminada ou modificada.

Sob este ponto de vista as constituições possuem um núcleo de provisões normativas e axiológicas que não podem ser substituídas ou emendadas de forma ordinária, nem atacadas por manifestações jurídico-discursivas de agentes institucionais não legitimados democraticamente. Isto se dá, pois este núcleo de princípios, valores e previsões normativas essenciais ao corpo jurídico-constitucional são resultado da materialização de uma identidade nacional e de heranças culturais inalteráveis canalizadas por forças históricas complexas (ANDERSON, 2008, p. 10). Tem-se uma percepção, portanto, da identidade constitucional enquanto uma base axiológica irredutível que sustenta e protege o texto constitucional, garantindo a unidade jurídica que as sociedades modernas solicitam (SMITH, 1991). 
A métrica amigo/inimigo que orienta o pensamento schmittiano a uma compreensão da alteridade como variável de risco à unidade da comunidade política, também se decanta como elemento constitutivo desta abordagem apriorística de identidade constitucional. Ao pressupor que a democracia solicita a existência de um "demos homogêneo", Carl Schmitt exclui da ambiência juspolítica a possibilidade do pluralismo e pauta seu entendimento de estabilidade estatal na construção de uma identidade - nacional e constitucional - alheia às manifestações discursivas que possam desestabilizar a unicidade da decisão política fundamental que engendra o texto constitucional (MOUFFE, 2015).

A constituição deveria, assim, expressar as memórias e o desejo de conviver que une os cidadãos de uma nação e os insta a respeitar a herança social legada às gerações futuras. $\mathrm{O}$ instituto da identidade constitucional, portanto, é a princípio utilizado como conceito jurídico de dimensão política, reconhecendo a constituição como componente jurídico nascido do amálgama de abstrações que definem a unidade política da nação. Esta corrente dogmática estabelece, pois, uma episteme que compreende a identidade constitucional como o espírito de uma cultura constitucional. Segundo Pierre Bon (2014, p. 180), a princípio a identidade constitucional não se dissocia da ideia de identidade nacional, tendo como função primordial estabelecer limites à integração jurídica à sociedade supranacional e determinar balizas à revisão e reforma constitucional.

Esta percepção de identidade constitucional ao decantar-se na atuação judicante de tribunais constitucionais europeus é instrumentalizada como argumento jurisprudencial retórico e anacrónico que distância o conceito de sua premissa jusfilosófica de reconciliação do fenômeno constitucional às transformações políticas e sociais que orbitam o direito doméstico. O instituto da identidade constitucional é utilizado, então, enquanto um conceito jurídico impreciso para negar a integração dos Estados europeus ao contexto multicêntrico de proteção aos direitos humanos ou de integração regional, refutando o Direito Internacional como faceta complementar às provisões do direito doméstico.

Ao presumir que mutações constitucionais que procuram a transnacionalização da dogmática normativa pátria tem o condão de aniquilar ou eliminar a constituição, esta corrente de pensamento deixa de compreender o texto constitucional como resultado de um desenvolvimento evolutivo e reflexivo da comunidade política (LUHMANN, 1996). Assumir a identidade constitucional como a "alma intangível da nação" (POLZIN, 2017, p. 1615), é, portanto, ignorar a força transformadora da Constituição em seu viés político, que garante a substituição de uma ordem jurídica por outra quando da incongruência dos valores sociais 
com o direito legislado (ruptura) ou sua adaptação à uma nova realidade política e social (mutação).

\subsection{A identidade do sujeito constitucional: a matriz dogmática de Michel Rosenfeld}

A noção de identidade constitucional associa-se à reforma e pluralismo do fenômeno jurídico-constitucional pátrio quando interpretada sobre o prisma de teóricos norteamericanos. Assim, com Michel Rosenfeld (2008) a doutrina ganha um substrato conceitual novo, de modo que a "identidade" já não se refere pontualmente à constituição, mas ao sujeito constitucional (constitutional subject). Este sujeito - acompanhando a influência psicanalítica de matriz lacaniana e hegeliana - é descentrado, de modo que não se confunde com o "Eu constitucional" (constitutional self).

Desta forma, na teoria de Michel Rosenfeld, enquanto as institucionalidades democráticas e a comunidade política são o constitutional self, o sujeito constitucional é compreendido enquanto matéria (subject as matter), ou seja, a substância fática a ser modulada em sede hermenêutica e legislativa, a fim de integrar o sistema jurídico dogmático pátrio. A identidade do sujeito constitucional denota, pois, invariavelmente uma identificação coletiva de natureza normativa - mas não meramente textual ou formal - que emerge dos movimentos hermenêuticos de (res)significação do fenômeno constitucional.

Logo, toda transformação política ou adaptação normativa que acontece em dada comunidade política (constitutional self) suscita (re)construções que ampliam ou restringem a autoimagem do sujeito constitucional. A matéria constitucional reflete, pois, a realidade sociopolítica e assenta uma contrafactualidade - isto é, uma suplementação normativa do real - que se posta no esquadro jurídico-constitucional da nação como um "vir a ser", uma conciliação do passado dos constituintes com o futuro das gerações vindouras, que sob a égide da constituição construirão sua comunidade política (ROSENFELD, 2008).

Abrangendo tanto a produção da constituição, quanto a interpretação constitucional subsequente, a reconstrução da identidade do sujeito constitucional engendra, assim, uma questão intergeracional, que alcança tanto o poder constituinte originário, quando o reformador (ROSENFELD, 2008). A contrafactualidade da identidade do sujeito constitucional, assim, evidencia a base desconstrutivista de teoria, que pressupõe ser todo texto uma singularidade, “[...] mesmo que [...] sua singularidade seja somente perceptível por meio da possibilidade de sua condição iterável, a possibilidade de que ele possa ser 
transmitido, e se comunica para além de qualquer contexto supostamente original" (WOLFREYS, 2007, p. 82).

É diante desta dimensão intergeracional e contrafactualidade da identidade constitucional, que se assume que o sujeito constitucional forja sua identidade mediante procedimento discursivo de assimilação e exclusão das diferentes manifestações identitárias que constituem o Estado Democrático e que procuram sua conformação ao corpus constitucional. Somente há sentido em pensar a identidade do sujeito constitucional idealizada por Rosenfeld dentro de uma "estrutura diferencial", onde o constitutional self forja um substrato jurídico que o identifica como uma unidade social decorrente de relações de reconhecimento mútuo à nível jurídico, embora esse processo de identificação englobe, também, o reconhecimento social e o compartilhamento de valores e significados, tal qual na leitura de George Mead (1934, p. 281) sobre construção da identidade social.

Tem-se, portanto, que a identidade constitucional emerge de um processo dialógico dentro das institucionalidades democráticas, representando o amálgama das aspirações políticas hegemônicas, constituindo-se, pois, não como o reflexo jurídico de uma identidade nacional inalterável e de interesses individuais e paixões políticas que se decantam no processo de constitution-making, mas a expressão normativa de um pluralismo abrangente que busca reconciliar diferentes identidades existentes no tecido social, conflitos morais e tensões entre bens da vida em um esquadro político-constitucional unívoco e homogêneo.

A materialização desta identidade constitucional se dá no discurso intersubjetivo que vincula todos os atores humanos que estão e serão reunidos pelas normas constitucionais escreve Rosenfeld (2010, p.40) - de modo que ela é circunscrita ao discurso jurídicoconstitucional prolatado pelo intérprete último da constituição. A identidade constitucional depende, desta forma, das múltiplas interpretações possíveis do texto constitucional dentro de um contexto aberto a transformações, sendo a reconstrução da identidade em essência uma seleção das manifestações identitárias e discursivas coerentes com a facticidade da comunidade política e com a base axiológica do constitucionalismo realizada pelos intérpretes constitucionais.

Sempre aberto à elaboração e revisam, o sujeito constitucional, contudo, detém uma natureza de incompletude, posto que o constitutional self precisa reiteradamente negar sua herança e tradição constitucional - o que Rosenfeld (2008, p. 30) classifica por um passado pré-constitucional que reflete a identidade da comunidade política pré-moderna. Logo, a fim de preservar a sua viabilidade e manter-se historicamente acessível, o sujeito constitucional 
precisa atualizar-se segundo a realidade política e institucional vigente. Por isso fala a teoria em reconstrução da identidade do sujeito constitucional e assimilação de novas identidades e manifestações discursivas - sejam elas locais, transnacionais ou extraestatais.

Ao conciliar estas necessidades divergentes dentro de um espectro constitucional unívoco, o sujeito constitucional contribui na formação de uma identidade que toma o Outro como referencial, transcendendo sua própria subjetividade para estabelecer uma constituição jurídica e política - que reflete um pluralismo normativo abrangente, que respeita tanto o ethos constitucional consolidado pelo poder constituinte, quanto às prerrogativas axiológicas e normativas definidas pelo constitucionalismo global. A forte matriz pluralista da proposta de reconstrução constitucional idealizada por Rosenfeld, se retroalimenta da noção de obrigação ética em relação ao Outro - revisitando uma concepção de justiça que se decanta no pensamento derridiano e na filosofia de Emmanuel Levinas (CRITCHLEY, 2014, p. 47).

Esta reconciliação com o Outro constitui a essência da teoria da identidade do sujeito constitucional, de modo que a formação da identidade se daria por heteroidentificação, isto é, processos através dos quais a comunidade política introjeta uma imagem oferecida de fora. Adota-se, assim, a perspectiva da alteridade - interna ou externa à comunidade política - para construir a singularidade (SAFATLE, 2020, p. 34). É precisamente no Outro que se encontram similitudes que são cristalizadas no tecido constitucional e divergências que são negadas, haja vista sua inadequação ao espaço simbólico comum que estrutura os regimes democráticos e o constitucionalismo global ocidental. Ou seja - recordando Chantal Mouffe (2015) - “as exclusões são encaradas em termos políticos, não em termos morais” (MOUFFE, 2015, p. 121).

\section{A IDENTIDADE INTERAMERICANA DO SUJEITO DE DIREITOS HUMANOS}

Não obstante as colaborações que a escola norte-americana estabelece à análise da identidade constitucional, sua natureza estritamente eurocêntrica é duramente criticada por teóricos como Mark Tushnet (2010), Jürgen Habermas (2017) e Gianluigi Palombella (2010). Por conseguinte, dada a carência de análises sobre a reconstrução da identidade constitucional no contexto latino-americano, importa compreender como, na América Latina, o discurso jurídico propalado pelo órgão jurisdicionado do Sistema Interamericano de Proteção aos Direitos Humanos (SIDH) estimula a consolidação de uma identidade constitucional transnacional. Para tanto, propõe-se a compreensão de uma identidade interamericana do sujeito de direitos humanos. 
No sistema jurídico contemporâneo de proteção aos direitos humanos há inevitavelmente a necessidade de solucionar os problemas jurídico-constitucionais segundo uma interlocução ou convergência da ratio decidendi de decisão domésticas e de construções normativas estrangeiras ou internacionais e a natureza isomórfica das controvérsias que envolvem os direitos humanos solicita a disposição estatal para o aprendizado recíproco entre as ordens locais, internacionais e extraestatais (DUPUY, 2007, p. 2). Logo, garantia e proteção dos direitos humanos não ficam restritas à atuação isolada dos Estados, convertendose em uma empreitada conjunta de agentes nacionais e órgãos internacionais.

A imbricação da ordem constitucional pátria com as manifestações discursivas do Direito Internacional dos Direitos Humanos contextualiza, assim, a identidade do sujeito constitucional ao enquadramento político e jurídico transnacional. Neste sentido, a implementação das convenções regionais de direitos humanos, pondera Rosenfeld (2010, p. 265), permite a elaboração aprofundada de uma identidade do sujeito dos direitos humanos (identity of human rights subject), garantindo a convergência e integração necessárias à relação evolutiva entre Direito Constitucional e Internacional. Esta reconciliação do sujeito constitucional a sua contraparte internacional é fundamental à homogeneização da interpretação e aplicação da normativa internacional a nível regional.

A aproximação dos Estados ao ethos pluralista consagrado no discurso jurídico internacional - onde, entende Rosenfeld (2010, p. 276), concepções de dignidade, liberdade e igualdade são normativamente fixadas e universalizadas - garante a concretização de um critério jurídico e moral exequível e legítimo, através do qual processos de convergência e divergência à dogmática dos direitos humanos se estabelece domesticamente. Assim, escreve o autor:

"[...] integrar o ethos pluralista na ordem constitucional esculpida pelos Estados-nação facilitará a aceitação de uma maior diversidade, ao fornecer ferramentas eficazes para desafiar o status quo constitucional e as limitações estabelecidas na identidade constitucional prevalecente [...] Assim, se exclusões de certos modos de vida se mostram contrárias à uma concepção de dignidade consistente com o ethos pluralista então essas exclusões deveriam ser declaradas inconstitucionais" (ROSENFELD, 2010, p. 276).

Pode-se assumir, destarte, que à proporção em que os estados latino-americanos ratificam a Convenção Americana e reconhecem a jurisdição contenciosa da Corte IDH, suas institucionalidades democráticas se inserem em um novo esquadro jurídico que insta a ordem constitucional pátria - segundo alavancas procedimentais (ratificação e recepção de um tratado) e materiais (necessária convergência a um compromisso moral e normativo de 
garantia e promoção dos direitos humanos) - a ser complementada e modulada pelo discurso jurídico internacional construído pela Corte IDH em suas sentenças, opiniões consultivas e medidas provisionais, internalizando a "identidade interamericana do sujeito dos direitos humanos" que se consolida na expressão discursiva da Corte IDH.

Tal complementação é salutar, posto que a assimilação do discurso da Corte IDH pelos Estados-membros viabiliza a introjeção da gramática dos direitos humanos em sua estrutura político-institucional e normativa, abrindo margem para um controle de convencionalidade construtivo e destrutivo. A adequação ao discurso interamericano concede, pois, credibilidade à argumentação dos agentes políticos e jurídicos, bem como pode servir de referencial paradigmático através do qual se conduz a argumentação na esfera legislativa e jurídica, exercendo função estrutural de validade dos argumentos estatais.

Pode-se imaginar, pois, que o discurso jurídico internacional da Corte IDH alberga uma identidade especial, limitada pelas exigências e compromissos internacionais firmadas pelos Estados-membros e modelada segundo as singularidades normativas e institucionais que definem o contencioso internacional do SIDH. Esta "identidade interamericana" congrega, pois, o standard normativo-axiológico qualificado regionalmente como força motriz para promoção de um mandato transformador do Sistema Interamericano, interessado sobremaneira na superação da violência generalizada, da exclusão social e da debilidade das instituições nacionais. (BOGDANDY, 2019).

Desta forma, o conceito que aqui se procura construir - a identidade interamericana significa o núcleo duro de percepções jurídicas sustentadas pela Corte IDH, resultado da interpretação evolutiva da CADH e direcionada aos Estados-membros através das decisões da Corte IDH no uso de sua competência contenciosa. Esta identidade interamericana do sujeito de direitos humanos constituiria, desta forma, a racionalidade jurídica que deve se aderir à identidade constitucional dos Estados-membros, servindo de catalisador para o desenvolvimento e revisão constitucional e, consequentemente, reagrupando as argumentações legislativas e jurisdicionais segundo a lógica internacional de afirmação dos direitos humanos, especialmente de grupos vulneráveis.

Assim, a interlocução do discurso constitucional com dotações de conhecimento jurídico produzidas por atores internacionais judiciais e quase-judiciais tem efeito direto na redefinição da identidade constitucional, sobremaneira ao se recordar que o discurso jurídico internacional tem sido veículo definitivo para a concreção de expectativas jurídicoconstitucionais. É o caso, por exemplo, das comunidades indígenas ou dos pleitos por 
consolidação democrática na América Latina, que buscam no projeto transformador capitaneado pela Corte IDH, o dínamo necessário para movimentar - seja por responsabilização ou shamming internacional - as omissas institucionalidades democráticas (BOGDANDY, 2019).

As modulações normativas promovidas pelo discurso interamericano contra leis de autoanistia são exemplo paradigmático de reconstrução da identidade do sujeito constitucional após reconciliação com a identidade interamericana. A comunicação transjudicial (SLAUGHTER, 2004) dos tribunais constitucionais de Argentina (caso Simón e Mazzeo), Uruguai (caso Nibia Sabalsagaray) e Chile (casos Rol 3215-05 / Rol 559-4), exempli gratia, colaboraram substancialmente com a ruptura da identidade pré-constitucional autoritária que ainda vicejavam nos sistemas de justiça da latino-americanos, garantindo a evolução do fenômeno constitucional em consistência com a realidade fática da redemocratização.

Como exemplos de reconstrução e transnacionalização da identidade do sujeito constitucional pode-se citar, ainda: (i) a emenda constitucional no Chile que garantiu liberdade artística, promovida enquanto cumprimento de sentença de Olmedo Bustos v. Chile; (ii) a declaração de inconstitucionalidade das disposições da lei de segurança nacional equatoriana após condenação em Zambrano Velez v. Equador; (iii) a modificação do código penal argentino, após manifestação da Corte IDH em Kimel v. Argentina, (v) revisão judicial promovida pela Corte Constitucional da Colômbia em sentença C-228/02, adotando conceito de reparação de vítimas desenvolvido pela Corte IDH e (vi) a tipificação do crime de feminicídio no México em função de debates instigados pelo caso Campo Algodoeiro v. México; (vii) no Brasil, a Emenda Constitucional 35/01, estabelecida em função do caso Barbosa de Sousa e outros v. Brasil.

Fica, assim, evidente como a inclusão do discurso jurídico da Corte IDH no necessário processo de reconstrução da identidade do sujeito constitucional

[...] oportuniza aos procedimentos democráticos e a interpretação dos
direitos fundamentais conteúdos capazes de influenciar na construção da
identidade não substitui as interpretações constitucionais estatais, mas
influencia na oferta de subsídios capazes de frear excessos e estimular
debates acerca do conteúdo dos direitos fundamentais (MAGALHÃES,
2015, p. 201)

Resulta daí que a inclusão da identidade interamericana ao esquadro constitucional pátrio - conforme vislumbrado nos exemplos citados - orienta à supressão de identidades préconstitucionais antagônicas à lógica jurídica do pluralismo e da democracia liberal. A 
conformação de uma identidade interamericana ao sujeito constitucional garante à comunidade política envolvida o desenvolvimento de um sistema constitucional que reflete as propostas de pluralização das perspectivas axiológicas de dignidade humana, comprometendo-se com a consolidação de uma estrutura jurídica ciente de suas limitações e disposta a apreender no Outro singularidades e diferenças que lhes são auspiciosas.

O sujeito constitucional, entretanto, ao pretender reconstruir-se mediante internalização do discurso jurídico internacional vincula-se impreterivelmente a critérios substantivos e procedurais pré-estabelecidos pelo poder constituinte originário (quórum mínimo para emendas constitucionais, cláusulas pétreas e limites materiais à mutação constitucional promovida pelos tribunais, por exemplo). Assim, conclui Rosenfeld:

[...] o sujeito constitucional se encontra em uma posição que o obriga a forjar a sua identidade por meio de um discurso constitucional embutido em uma linguagem comum, que une o eu constitucional com seus múltiplos outros. Além disso, este discurso constitucional deve se basear em um texto que deve ser colocado em seu contexto adequado, levando em consideração as restrições normativas e factuais relevantes (ROSENFELD, 2010, p. 41).

\section{RESTRIÇÕES À RECONSTRUÇÃO DE IDENTIDADE CONSTITUCIONAL: UMA ANÁLISE A PARTIR DA EXPERIÊNCIA BRASILEIRA}

A fim de compreender como em definitivo a Corte IDH impacta a reconstrução da identidade do sujeito constitucional, a reformulação do discurso constitucional mediante controle de convencionalidade e fertilização jurisprudencial cruzada é assumido, nesta pesquisa, como principal instrumento de transnacionalização da identidade do sujeito constitucional. Ao introduzir novos elementos na estrutura política - aduz Lorenzetto (2016, p. 72) - as decisões judiciais harmonizam os novos elementos acrescidos na tessitura constitucional com aqueles que já se encontravam estabelecidos, recombinando-os de forma a compor uma base normativa inteligível e cogente.

Merece realce, contudo, a aproximação de múltiplos discursos e identidades será selecionado por um "projeto de reconstrução constitucional" (ROSENFELD, 2010, p. 90). Neste prisma, Rosenfeld (2010, p. 63) argumenta que a seleção de qual identidade se adere ao sujeito constitucional quando de sua reconstrução se vê limitada pelas balizas estruturais impostos pela ordem constitucional e pela herança sociocultural da comunidade política. As balizas estruturais dizem respeito a restrições formais definidas pelo constituinte ou os costumes constitucionais e princípios ideológicos de alcance geral (quórum mínimo para 
emendas constitucionais ou limites materiais que restringem a hermenêutica constitucional, e.g.).

O material que será objeto da movimentação jurídico-discursiva que engendra a reconstrução da identidade do sujeito constitucional é fornecida, entretanto, pelas forças políticas que Michel Rosenfeld (2010) nomina por "herança sociocultural da comunidade política". Ao se recordar que o processo de (re)construção constitucional é moldado pela troca dinâmica de forças opostas de assimilação e exclusão, pode-se traduzir este segundo nível de restrição à reconstrução como as movimentações culturais hegemônicas que restringem e avançam às deliberações democráticas em determinada matéria relativa a direitos fundamentais.

Nisto, há de se recordar que o discurso jurídico-constitucional possui uma dimensão ideológica, expressando sempre a compreensão de um grupo acerca da experiência social (MOREIRA, 2017). Por demais, a articulação do discurso jurídico-constitucional também se vê controlado por uma "elite simbólica" (BOURDIEU, 2013, p. 171) que detém relativo poder para tomar decisões quanto a estilo, forma e tema a ser abordado (DIJK, 018, p. 45). Logo, o discurso jurídico tratar-se de objeto de manipulação e dominação política, estando, pois, suscetível à alopoiese do direito pensada por Marcelo Neves (2018, p. 148), quando “[...] os agentes do sistema jurídico estatal põem de lado o código diferença lícito/ilícito e os respectivos programas e critérios, conduzindo-se primária e frequentemente com base em um injunções diretas da economia, do poder, das ações familiares, etc."

Assim, as ideologias sociais e disposições políticas que se condensam enquanto heranças socioculturais de um passado pré-constitucional autoritário, elitista, estatocêntrico e pouco laicizado, se materializam na narrativa que conforma o discurso jurídico dos tribunais, impedindo o reconstruir do direito posto e o questionamento de posições sociais e decisões institucionais que violam a integridade e identidade de grupos minoritários ou ignoram as obrigações internacionais firmadas pelos Estados, minorando o discurso dos direitos humanos.

É, portanto, a dimensão ideológica do discurso jurídico-constitucional que estabelece o distanciamento normativo que separa quais identidades são restringidas de compor texto e discurso constitucional e quais gloriosamente se emancipam do factual e se cristalizam como norma constitucional contrafactual. Estas observações deixam transparecer que a (re)construção da identidade do sujeito constitucional acontece à mercê de escolhas - não apenas formais, mas simbólicas também - postas pelas instituições democráticas e por 
posições hegemônicas conservadoras que dispõem de primazia sócio-ontológica capaz de sobrepor seus interesses aos ditames do constitucionalismo.

São estas movimentações culturais hegemônicas que impedem, por exemplo, a internalização do discurso supranacional nos Tribunais Europeus (caso Solange I, na Alemanha) ou a pluralização do discurso constitucional na Suprema Corte Americana, de modo a incluir manifestações da comunidade LGBTQIA+ (caso Lawrence vs. Texas) ou identidades étnicas (caso Dred Scott v. Sandford). A reconstrução da identidade constitucional trata-se, então, essencialmente de um confronto histórico e institucional de significados, fatores sociais e oposições normativas, entende Gianluigi Palombella (2010, p. 663). Em verdade, o processo constitucional envolve uma constante dialética entre a conformação do fenômeno constitucional enquanto um sistema social eficaz na concretização de direitos e sua deturpação em figura retórica do discurso do poder (NEVES, 2018).

Anna Śledzińska-Simon (2015, p. 154), em complemento, destaca que uma decisão política, legislativa ou judicial da comunidade política pode conduzir tanto à abertura cognitiva ao Outro, quanto a um movimento de isolamento, evitando a alteridade (avoid the other) imanente ao pluralismo jurídico - isto é, assumindo uma noção essencialista e schmittiana da identidade constitucional. A prevalência de decisões políticas e jurídicas que conduzam a uma identidade sobremaneira intersubjetiva dependerá, entende a autora, apenas do contexto no qual se insere a reconstrução (variável contextual de natureza política ou social) e do assunto (matéria discutida em sede legislativa ou hermenêutica e fornecida pela herança sociocultural).

Neste prisma, recorrendo ao princípio da integridade, Michel Rosenfeld pondera sobre o risco da reconstrução constitucional converter-se em instrumento em prol de abordagens dissociadas dos limites normativos estabelecidos pelo constitucionalismo liberal. Assim, dirá Rosenfeld:

[...] nem todos os produtos de nossa imaginação contrafactual resultam em uma reconstrução útil e aceitável. Um contrafactual que somente justifique o status quo a todo o custo [...] representaria um uso impróprio da construção. Dworkin insiste que a interpretação judicial reconstrutiva gira em torno de dois requisitos fundamentais: primeiramente a aceitação de determinados princípios deontológicos [...] e, em segundo lugar, adoção de um padrão coerente e uniforme, especificamente da integridade, que requer a consistência de qualquer nova interpretação judicial com o corpo das interpretações judiciais passadas" (ROSENFELD, 2008, p. 46)

Tem-se, pois, que os termos em que se coloca a reconstrução de identidade do sujeito constitucional são significativamente determinados por condições estruturais, forças 
ideológicas e variações contextuais. Logo, pode-se assumir que, no Brasil “[...] o desenvolvimento de um constitucionalismo liberal sem o pano de fundo de uma tradição sólida de direitos e garantias individuais" (AVRITZER, 2019, p. 27) e as influências discursivas hegemônicas controladas por uma elite simbólica interessada na preservação de regimes autoritários constituem os principais óbices à transnacionalização da identidade do sujeito constitucional, desmontando a pretensão de guiar o fenômeno constitucional rumo ao discurso internacional dos direitos humanos.

Fato é que, após a transição política, o Brasil viveu um processo constituinte respaldado por interesses de grupos sociais múltiplos, garantindo a constitucionalização de direitos sociais e relativa fuga ao elitismo de constituições pretéritas. A Constituição Federal de 1988, desta forma, integra o Estado Democrático de Direito ao redefinir o pacto político, reiterando a primazia da dignidade humana e assumindo o pluralismo enquanto possibilidade de manifestações das diferenças. A nível de reforma constitucional a Emenda nº 45/2004, simulacro de uma incorporação definitiva do Direito Internacional dos Direitos Humanos na rotina constitucional do país, eleva normatividade os tratados de direitos humanos, garantindo-lhes status constitucional.

Tem-se, pois, que a reconstrução constitucional no Brasil dificilmente encontra-se restringida por balizas estruturais, especialmente se se recorda o forte viés neoconstitucional que caracteriza o Supremo Tribunal Federal (STF) nos últimos 10 anos - amplamente permeável a influxos teóricos advindos de uma episteme pós-positivista de hermenêutica constitucional. Nada obstante, a atuação judicante do STF parece ignorar a ratificação da CADH em 1992 e reconhecimento da jurisdição contenciosa da CtIDH em 1998. Apesar dos compromissos formais que o estado brasileiro estipula com a jurisdição interamericana, o STF - agente principal da reconstrução constitucional - demonstra resistência às transformações constitucionais que deveriam advir da inclusão da comunidade política na realidade interamericana de um sistema multinível de proteção aos direitos humanos.

Uma análise da jurisprudência do STF formulada entre 2010 e 2020 - isto é, desde a condenação do Brasil em Gomes Lund v. Brasil - em sede de controle abstrato de constitucionalidade 13 casos fazem referência direta e indireta ao discurso interamericano são elas: (i) ADPF 144, (ii) ADPF 153, (iii) ADPF 132/ADI 4277, (iv) ADI 4815, (v) ADI 387, (vi) ADI 4275, (vii) ADI 5617, (viii) ADI 4451, (ix) ADI 5243; (x) ADC 42, (xi) ADC 43, (xii) ADI 4439 e (xiii) ADI 3239. Nestes julgados, o diálogo transjudicial viabilizou o uso do discurso da Corte IDH como obter dictum das decisões domésticas, canalizando a 
argumentação do STF em convergência com a identidade interamericana do sujeito de direitos humanos, ainda que de forma superficial.

Importa ressalvar, entretanto, o uso meramente imagético e, por vezes, errôneo da jurisprudência da Corte IDH. Sem cotejar a interpretação das decisões e opiniões consultivas, nem preocupando-se em reconhecer o esforço pedagógico que o discurso interamericano alberga, o STF converte-se em "[...] desviante que resiste em reconhecer as transformações costumeiras operadas na estrutura institucional, funções e no funcionamento do acesso, competência e eficácia das decisões e da jurisprudência da Corte IDH” (LEGALE, 2020, p. 512). Falta ao STF uma explicação ou uma distinção mais clara do caráter vinculante, definitivo e inapelável das sentenças da Corte IDH, é o entendimento de Siddharta Legale (2020).

Nesse sentido, julgados como a ADPF 132/ADI 4277 (união homoafetiva) - que promoveram, a partir de interlocução superficial com o discurso interamericano, ampliação material de direito à expressão identitária (identidade de gênero) invisibilizada pelo fenômeno constitucional pré-moderno - não podem ser percebidos como pontos de transnacionalização da identidade constitucional. Tratam-se, em verdade, de experiências de reconstrução constitucional meramente episódicas, viabilizadas por variáveis contextuais auspiciosas (ampla discussão na esfera pública, STF composto por ministros liberais, reiteração do pleito na arena jurídica, e.g.) e por matéria constitucional que não encontra resistência suficiente da herança sociocultural hegemônica para induzir a negação da reconstrução da identidade constitucional.

Por outro lado, experiências como a ADPF 153 (lei de anistia) - onde as movimentações socioculturais hegemônicas capitaneadas por grupos de interesse componentes da elite política do país estão em jogo - fornecem um momento severamente menos positivo à reconstrução de identidade constitucional. Esses dois exemplos deixam assente como o texto constitucional, no Brasil pós-1988, não se concretiza com um mecanismo ou paradigma de orientação das expectativas normativas e políticas, de modo que a assimilação de novas identidades e manifestações discursivas extra-sistêmicas são definidas por um projeto de reconstrução constitucional severamente subvencionado pelas condicionalidades político-ideológicas.

Adere-se a isto a fragilidade do discurso jurídico da Corte IDH, impreterivelmente dependente do grau de engajamento dos Estados e de seus tribunais constitucionais. O discurso da Corte IDH produz efeitos palpáveis apenas se encontra terreno político adequado 
para consolidar-se estruturalmente nas institucionalidades democráticas. O impacto positivo do SIDH quando da redemocratização no final do século XX, por exemplo, somente prosperou, pois o cenário político-social, com os relatórios da CIDH e condenação de Augusto Pinochet em 1998, era favorável a um discurso pró-direitos humanos (CAVALLARO; BREWER, 2008). Logo, a assimilação da identidade interamericana depende da capacidade e disposição dos tribunais constitucionais em reconhecerem um compromisso internacional com a integração regional do SIDH e com a consolidação democrática na região.

Os discursos jurídico-constitucionais que movem a reconstrução de identidade do sujeito constitucional no Brasil pós-1988 parecem, portanto, replicar a noção de identidade constitucional como instrumento retórico de recusa da integração da constituição a uma lógica internacional, protegendo a supremacia do texto e do discurso constitucional sob auspícios de uma percepção soberanista e pré-moderna. Isto permite sustentar que a identidade do sujeito constitucional pós-1988, embora pareça transnacional - haja vista a Emenda Constitucional no 45/2004, as interlocuções episódicas com a Corte IDH e o engajamento pós-positivista do STF - não assimilou a identidade interamericana, mostrando-se destacadamente divergente da construção normativo-axiológica que o discurso interamericano estipula.

\section{CONSIDERAÇÕES FINAIS}

Constituindo-se como expressão zetética do impacto político de renovações sociais e institucionais no constitucionalismo democrático, a lógica da identidade do sujeito constitucional alerta, assim, para a necessidade de harmonizar a constituição as novos elemento acrescido na tessitura social - desde que conciliável à identidade constitucional préexistente - mantendo, assim, o fenômeno constitucional atualizado a sua realidade sociopolítica. É neste prisma que o artigo argumenta como o discurso jurídico da Corte IDH está apto a pluralizar a identidade do sujeito constitucional, reconciliando-a com as noções de dignidade humana e o espírito democrático que animam o Sistema Interamericano desde sua criação em 1978.

Entretanto, observou-se ao fim da pesquisa que as experiências de construção e desenvolvimento da identidade constitucional são dependentes do contexto e de fatores relacionais. Assim, cada tentativa de reconstruir a identidade do sujeito constitucional mediante iniciativa discursiva do tribunal constitucional constitui experiência única, passível de sofrer influências de natureza estrutural, contextual ou ideológica. Isto se dá, pois ao 
conceber a reconstrução da identidade constitucional como um movimento essencialmente discursivo, a teoria de Michel Rosenfeld assume que o sujeito constitucional é o gerador interno de sua própria transformação, de modo que se o sujeito se desequilibra, a reconstrução de sua identidade sofre deformações.

Em outras palavras, a disposição do sujeito constitucional à adequação sociopolítica e jurídico-institucional mediante abertura e reinterpretação do texto/discurso constitucional fica suscetível a deturpações que possam advir de um momento constitucional desfavorável à pluralização da identidade constitucional ou da ausência de um ethos democrático que pense a reconstrução constitucional segundo um prisma pluralista e globalizado. Assim, as variáveis contextuais exógenas ao direito, a matéria objeto de deliberação e a herança sociocultural do país são decisivas na opção dos tribunais em conduzir uma reconstrução de identidade constitucional mediada por uma aproximação com agente internacional.

Resta então registrar, a título de síntese do pensamento, que a reconstrução da identidade constitucional se atesta como uma confrontação política, pautada na reconciliação de diferenças e modulação de interesses. O mérito da identidade constitucional é, contudo, sua condição plural e inacabada, que se articula pouco a pouco pela introjeção gradativa das identidades que, na disposição para reafirmar constantemente suas lutas por reconhecimento e ampliação material de direitos, superam os movimentos repressivos de um passado prémoderno essencialista. Logo, a identidade constitucional na realidade pós-tradicional se define não apenas pela sua diferenciação, mas especialmente por sua aproximação a identidades internacionais que necessariamente conformam o constitucionalismo ocidental.

\section{REFERÊNCIAS}

ANDERSON, B. Comunidades imaginadas: reflexões sobre a origem e a difusão do nacionalismo. São Paulo: Companhia das Letras, 2008.

AVRITZER, Leonardo. O Pêndulo da Democracia. São Paulo: Todavia, 2019.

BOURDIEU, P. Outline a theory of practice. London: Cambridge University Press, 2013.

BOGDANDY, Armin Von. O mandato transformador do Sistema Interamericano: Legalidade e Legitimidade de um processo jurídico extraordinário. Revista Brasileira de Políticas Públicas, Brasília, v. 9, n. 9, p. 232-252, 2019

CANOTILHO, J. J. Gomes. Direito Constitucional e Teoria da Constituição. Coimbra: Ed. Almedina, 2010, $1518 \mathrm{p}$. 
CAVALLARO, James; BREWER, S. E. Reevaluating regional human rights litigation in the 21 st century: The case of the IACHR. American Journal of International Law, v. 102, n. 4, 2008 , p. 821.

CRITCHLEY, S. Desconstrução e Pragmatismo: Derrida é um ironista privado ou um liberal público? In: MOUFFE, Chantal (Org). Desconstrução e Pragmatismo, São Paulo: Ed. Mauad X, 2014, p. 35-69.

DANTAS, Ivo. Teoria do Estado Contemporâneo. Curitiba: Editora Juruá, 2016.

DEL VECCHIO, Giorgio. Filosofía del derecho. Barcelona: Bosch Casa editorial, 1984

DUPUY, Pierre-Marie. The unity of Application of International Law at the Global Level and the Responsibility of Judges. In: European Journal of Legal Studies. v. 1. n.2. p. 1-33. 2007.

GIDDENS, Anthony. As consequências da modernidade. São Paulo: Ed Unesp, 1991

HABERMAS, J. A Inclusão do Outro. São Paulo: Ed. Unesp, 2017.

JACOBSON, Gary. Constitutional Identity. London: Harvard University Press, 2010.

LEGALE. Siddharta. A Corte Interamericana de Direitos Humanos como Tribunal

Constitucional: Exposição e análise crítica dos principais casos. Rio de Janeiro: Ed. Lumen Juris, 2020

LORENZETTO. Bruno Meneses. Caminhos do constitucionalismo à democracia. 2014. 323 f. Tese (Doutorado em Direito) - Programa de Pós-Graduação em Direito, Universidade Federal do Paraná, Curitiba, 2014.

LUHMANN, N. La costituzione come acquisizione evolutiva. In: ZAGREBELSKY, Gustavo. PORTINARO, Pier Paolo. LUTHER, Jörg. Il Futuro della Costituzione. Torino: Einaudi, 1996.

MAGALHÃES, Breno B. Pluralismo Constitucional Interamericano: leitura plural da Constituição de 1988 e o diálogo entre o Supremo Tribunal Federal e a Corte Interamericana de Direitos Humanos. 2015. 315 f. Tese (Doutorado em Direito) - Programa de PósGraduação em Direito, Universidade Federal do Pará, Belém, 2015.

MEAD, George H. Mind, Self and Society: from the stand pointy of a social behaviorist. Chicago: University os Chicago Press, 1934.

MONIKA, Polzin. Constitutional Identity as a constructed and a restless soul. German Law Journal, v. 18, n. 7, 2017, p. 1595-1616

MOREIRA, Adilson José. Direito, poder, ideologia: discurso jurídico como narrativa cultural. Revista Direito \& Práxis, v. 8, n. 2, 2017, p. 830-868.

MOUFFE, Chantal. Sobre o Político. São Paulo: Ed. WMF, 2015, 135 p. 
NEVES, Marcelo. A Constitucionalização Simbólica. São Paulo: WMF Martins Fontes, 2018.

PALOMBELLA, G. Structures and process in the constitutional self: coping with the future? International Journal of Constitutional Law, 2010, v. 8, n.3, 656-664

ROSENFELD, Michel. A identidade do sujeito constitucional, Trd. Menelick de Carvalho Netto, Belo Horizonte: Mandamentos, 2003.

ROSENFELD, Michel. The Identity of the constitutional subject: Selfhood, citizenship, culture and community. Routledge: Taylor \& Francis Group, 2010.

SAFATLE, Vladimir. Introdução a Jacques Lacan. São Paulo: Ed. Autêntica, 2020.

SLAUGHTER. Anne-Marie. A Global Community of Courts. In: Harvard International Law Journal. v. 44. p. 1-29. 2004

ŚLEDZIŃSKA-SIMON. Anna. Constitutional identity in 3D: A model of individual, relational, and collective self and its application in Poland. Oxford University Press: New York, 2015

SCHMITT, C. Constitutional Theory. Durham: Duke University Press, 2008.

SMITH, Anthony. National Identity. New York: Penguin Book, 1991.

TUSHNET, M. How do constitutions constitute constitutional identity? In: International Journal of Constitutional Law. v. 8 n. 3, 2010. p. 674

VAN DIJK, Teun. Estruturas do discurso e estruturas do poder. In: VAN DIJK, Teun. Discurso e Poder. São Paulo: Ed. Contexto, p. 40-85.

WOLFREY, J. Compreender Derrida. São Paulo: Editora Vozes, 2012. 